\title{
Species diversity, invasion success, and ecosystem functioning: disentangling the influence of resource competition, facilitation, and extrinsic factors
}

\author{
John J. Stachowicz*, Jarrett E. Byrnes
}

Section of Evolution and Ecology and Center for Population Biology, University of California at Davis, Davis, California 95616, USA

\begin{abstract}
Experimental manipulations and observational surveys often produce conflicting conclusions regarding the effects of native species diversity on community susceptibility to invasion. Both provide useful pieces of information, but typically each asks fundamentally different questions. Surveys tell us that locations with species-rich native communities are characterized by conditions that promote exotic species richness, whereas experiments tell us that, within a location, the loss of resident species increases the likelihood of the establishment of new species. In the present study, we apply observational data to a study of the consequences of species loss for invasion in order to assess the generality across scales and the relative importance of experimental results. We begin by using long-term recruitment data to explore how small-scale mechanisms of biotic resistance could operate on a landscape scale. We find that individual species have complementary seasonal recruitment patterns such that more diverse communities might be able to more consistently fill space that opens throughout the season, leading to reduced invasion success. However, field surveys of native and invader richness show that the slope of the relationship between native and invader diversity changes with the availability of resources (space) and the presence of habitat-forming foundation species. In these systems, biotic resistance appears to be important only when resources are scarce and foundation species are rare. Thus, we conclude that biotic resistance, as identified in experiments, is a consistent effect of diversity that can be explained mechanistically at even a landscape scale, but that it plays a dominant role only when total diversity is constrained by resource limitation. This situation is common in experimentally constructed communities, but may be less so in nature.
\end{abstract}

KEY WORDS: Diversity-invasibility $\cdot$ Sessile invertebrates $\cdot$ Competition $\cdot$ Facilitation $\cdot$ Recruitment Temporal niche $\cdot$ Diversity-ecosystem functioning

\section{INTRODUCTION}

In this paper we focus on the often-contested relationship between diversity and invasibility of a community by exotic (non-indigenous) species. This question relates to the broader theme of this Theme Section on the consequences of diversity for ecosystem functioning in 2 ways. First, exotic species invasions in marine systems can have major effects on the structure and functioning of ecosystems (Grosholz 2002). If diversity enhances invasion resistance, it may help to buffer ecosystems from some of these changes. Second, the major mechanism by which diversity is ex- pected to enhance invasion resistance is via more complete use of resources (e.g. Elton 1958, Case 1990, Byers \& Noonburg 2003, Tilman 2004). The effect of diversity on resource use should affect other critical ecosystem processes such as productivity, nutrient retention and cycling, and community stability. Furthermore, understanding the mechanistic relationship between diversity and invasibility bears directly on the questions of whether contemporary communities are saturated with species and the extent to which there are limits on local diversity. If communities are generally saturated, then the consequences of new species introductions may be severe, whereas if communities 
are generally unsaturated, the consequences of most invasions may be relatively minor. Thus, the study of diversity-invasibility relationships provides a lens through which many important basic and applied issues in ecology may be profitably addressed.

A review of the empirical literature (mostly from terrestrial plant ecology) highlights the lack of consensus on the strength and direction of the effects of diversity on community resistance to invasion (Levine \& D'Antonio 1999). The discordant results between studies employing observational and experimental approaches are a major characteristic of this 'debate'. Most observational studies find that more-diverse native communities support more invaders (e.g. Knops et al. 1995, Planty-Tabacchi et al. 1996, Rejmanek 1996, Wiser et al. 1998, Lonsdale 1999, Stohlgren et al. 1999). These studies are often conducted at large scales (e.g. 10 to $1000 \mathrm{~km}^{2}$ or more, but see Sax 2002, Dunstan \& Johnson 2004), involve many species, and are favored by some because they involve 'natural' communities. But many other factors correlated with diversity can affect the establishment and spread of invasions, confounding the interpretation of such studies (e.g. see discussion in Rejmanek 2003). In contrast, most (but not all) experimental manipulations (necessarily conducted at smaller scales) support the idea that species richness decreases invasion success (McGrady-Steed et al. 1997, Knops et al. 1999, Lavorel et al. 1999, Stachowicz et al. 1999, 2002a, Levine 2000, Naeem et al. 2000, Symstad 2000, Kennedy et al. 2002, Fargione et al. 2003). The most commonly offered mechanism underlying this result is that species differ, or are complementary, in their use of resources such that increasing the number of species decreases the success of future invaders by decreasing total resource availability (e.g. Stachowicz et al. 1999, 2002a, Naeem et al. 2000). Such experiments reveal the potential of diversity to reduce invasion success, but rarely assess whether diversity is important relative to other factors such as propagule supply, disturbance, or predation for generating patterns of invasion in the field (but see Levine 2000, Stachowicz et al. 2002a).

The apparent paradox created by contrasting observational and experimental results occurs because each approach has addressed fundamentally different questions. Observational approaches often answer the question of which sites have the most exotics in them and, thus, might be in need of greatest attention from management efforts. Experimental approaches, in contrast, address the consequences of species loss (declining diversity) for the susceptibility of a community to invasion. These 2 approaches offer subtly different pieces of information that can be drawn together to produce a broader understanding of the relationship between native and exotic species richness. Patches that support diverse native communities are likely to support many exotic species, because the characteristics that favor high native diversity also favor high exotic diversity (e.g. Davies et al. 2005). However, within a given patch, the elimination of a native species due to anthropogenic disturbance should increase the probability of a successful invasion (e.g. Shea \& Chesson 2002).

Because of the difficulty of conducting multifactorial experiments on large scales, observational studies can also help refine hypotheses about the relative role of diversity versus other factors and assess the applicability of small-scale mechanistic experiments to largerscale processes. For example, when combined with field experiments, observational approaches have clarified where the mechanistic effects of diversity are (and are not) important relative to environmental factors such as disturbance or propagule supply in determining patterns of exotic species richness (Levine 2000, Stachowicz et al. 2002a). In the present study, we use two complementary observational approaches to address the mechanistic relationship between diversity and biotic resistance. First, we examine long-term recruitment patterns from the field that address an explicit landscape-scale mechanism of biotic resistance. Secondly, we examine patterns of native and invader richness in the field at a single time point, but tease out factors that correlate with the ability of a community to support more species, allowing us to determine under what conditions biotic resistance is important. Both approaches have in common that mechanisms elucidated from experiments are incorporated, yet we still consider a larger spatial and/or temporal perspective. We close with broader implications of our findings for the role of species diversity on ecosystem functioning.

\section{STUDY SYSTEM}

We focus in this paper on subtidal sessile marine invertebrate communities (i.e. fouling communities) that occur worldwide on natural rock outcrops, as well as on man-made structures like docks, wharves, and pilings. Studies of the role of diversity in community invasibility have been conducted in few, if any, other marine systems of which we are aware. Fouling communities are comprised of a diverse array of solitary and colonial marine invertebrates, including ascidians (sea squirts), bryozoans, bivalve molluscs, tubebuilding polychaete worms, sponges, barnacles, and sea anemones. Most of these taxa are suspension feeders, relying on planktonic food. The limiting resource in these systems most often appears to be space (Osman 1977, Sutherland \& Karlson 1977, Stachowicz 
et al. 1999, 2002a), although sometimes competition for food and space can be difficult to separate (Buss 1979). Because these communities readily occur in harbors and ports, they have been colonized by many species from other biogeographic provinces that have been transported on the bottom of boat hulls or as larval stages in ballast water (Carlton \& Geller 1993, Ruiz et al. 2000). The fossil record for many of these organisms is poor (e.g. soft-bodied ascidians), so the actual status of some of these species as natives or invader is uncertain. All the species we refer to as 'native' were present in the system at the time that humans began studying them, usually in the mid-1800s (see references in Van Name 1945). We thus define as 'exotic' any species that was not recorded in the first comprehensive monographs for a taxonomic group from a given region. While our distinctions may not reflect actual native versus exotic status, they separate species that have been resident for a lengthy period of time and those that are recent, documented invaders into an already established community.

We manipulated the species richness of sessile marine invertebrate communities in Long Island Sound, Connecticut, USA, and challenged these communities with different potential invaders (Stachowicz et al. 1999, 2002a). We found that in all cases invasion success decreased with increasing resident diversity (Fig. 1A). This was because individual species were complementary in their temporal patterns of space occupation. Individual species all fluctuated in abundance, but these fluctuations were out of phase, such that at least 1 species was always abundant and occupying space in the high-diversity treatments, whereas there were periods of high space availability in the low-diversity treatments (Fig. 1B). Thus, more diverse communities exhibit changes in the relative abundance of species over time, but maintain consistently high occupancy of space, while those with fewer species experience longer periods of high space availability. This is in agreement with theory that suggests, more broadly, that diversity should enhance the stability of community properties (i.e. space occupancy), but that it should decrease or have no effect on the stability of individual species' populations (May 1974, Tilman 1996). We confirmed that resource availability was a major contributor to invasion success by holding diversity constant, but manipulating space availability. These experiments showed a strong positive relationship between space availability and invasion success, and that even a brief window of open space (2 wk) could increase invasion success by an order of magnitude (Stachowicz et al. 2002a).

Studies in terrestrial plant communities have stressed that fluctuating resource availability in general often enhances invasion success (Davis et al.
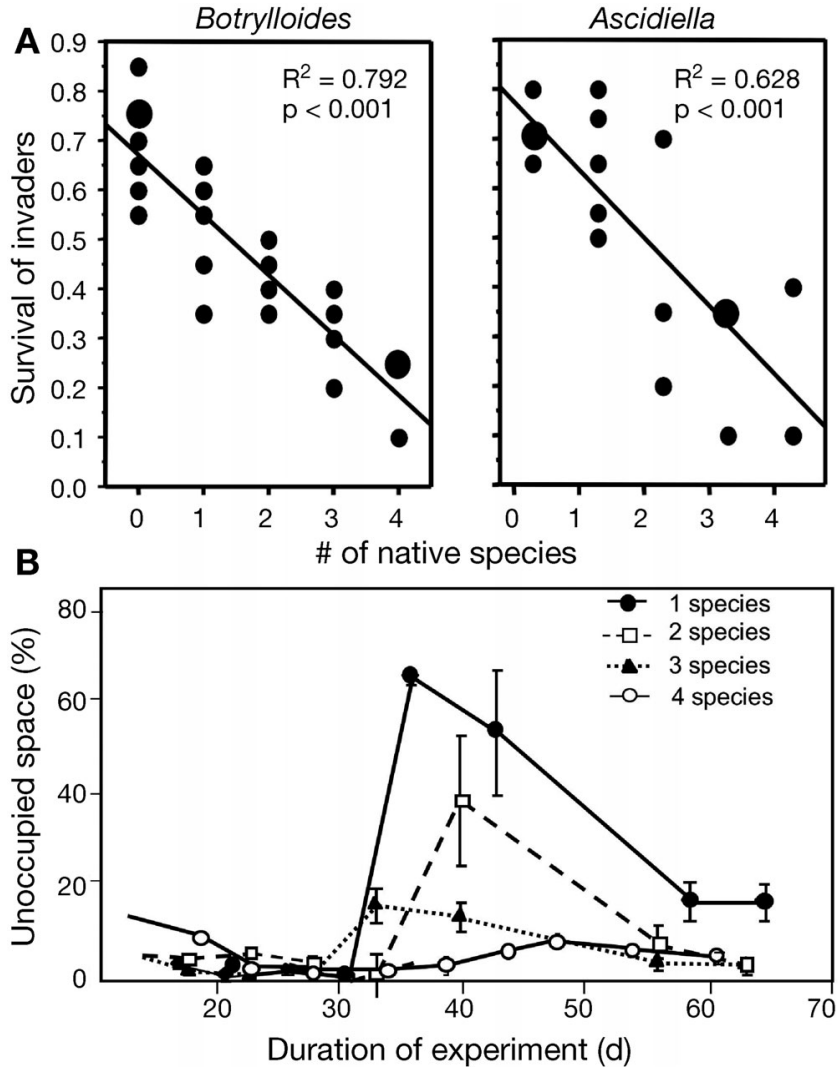

Fig. 1. Effects of experimental manipulation of diversity on the success of introduced species (from Stachowicz et al. 2002a). (A) Survival of the colonial ascidian Botrylloides violaceous and the solitary ascidian Ascidiella aspersa as a function of resident community species richness. Larger dots indicate 2 data points that lie on top of one another. (B) Resource (space) availability over time as a function of initial community richness (mean $\pm \mathrm{SE}$ ); note that all communities are capable of occupying all the space, but that communities experience peaks in resource availability that are greater in communities with fewer species. See 'Study system' section and Stachowicz et al. (2002a) for details

2000), so we suspect that this mechanism is applicable to a wide variety of ecosystems in which diversity affects resource availability. The seasonal or temporal niches critical to the operation of this mechanism are likely to be common in a variety of environments, including such diverse taxa as marine invertebrates and herbaceous plants (Chesson 2000, Stachowicz \& Tilman 2005), phytoplankton (Rynearson \& Armbrust 2004, Duffy \& Stachowicz 2006 [in this Theme Section]), migratory fishes (Klimley et al. 2005), and any other groups with a strong seasonality to their distribution and abundance. Thus, while the identity of limiting resources may differ across ecosystems, we expect the patterns and conclusions of work on these communities to be applicable to any resource-limited system. 


\section{CONSEQUENCES OF SEASONAL NICHES FOR RESOURCE USE}

What underlies the differences in seasonal phenologies among species that lead to the temporal complementarity illustrated in Fig. 1? Despite differences in growth forms, marine invertebrates on hard substrates seem to compete primarily for space, the likely limiting resource. However, each species may differ in growth rates, patterns of mortality, in the timing, duration and magnitude of reproductive output, in the degree to which they are capable of local recruitment, and in their response to biotic and physical stresses (e.g. McDougall 1943, Osman 1977, Sutherland \& Karlson 1977). In seasonal environments, where conditions change predictably, each species thus may have a temporal or seasonal niche. These seasonal niches appear to provide the basis for complementary effects of species on resource use and invasion resistance (Fig. 1B; Stachowicz et al. 2002a).

While the results shown in Fig. 1 can largely be attributed to patterns of differential mortality in opening space to be invaded, when considering large spatial scales, stochastic events guarantee that there will always be patches of free space open to invaders in a dynamic marine environment. Whether a recruit of a new species can thrive and survive in an area depends on its ability to outcompete recruits of residents settling at the same time. Higher levels of total resident recruitment can lead to more intense competition and a lower probability of survival of recruits of nonresident species. If all resident species recruited during a single time interval, invaders would have a large window of opportunity during which establishment would be relatively easy. In contrast, if communities possess either 1 or more species that recruit at constant high densities or if species have complementary seasonal phenologies with respect to recruitment, creating constant high levels of recruitment through temporal complementarity, then invasion resistance should increase with diversity at large spatial scales.

To assess the degree to which the species on which we performed our experiments exhibit temporal complementarity in recruitment, we performed weekly surveys of recruitment of invertebrates onto artificial substrates (for full methods see Stachowicz et al. $2002 b)$. Briefly, the data consist of weekly censuses of newly settled sessile marine invertebrates on 4 panels of $100 \mathrm{~cm}^{2}$ suspended approximately $1 \mathrm{~m}$ below the water's surface. These data have been taken during the recruitment season since 1991 and continuously since 1997.

One sample year's worth of these data demonstrates that each species has a seasonal pattern of recruitment that appears to be complementary in time to those of other species (Fig. 2A, see below). If we assume that these reproductive cycles are dependent primarily on abiotic factors and that this leads to different seasonal patterns in adult abundance, then we can use seasonal patterns of recruitment to predict the effect of diversity on resource availability (space) for new exotic species. The effects of seasonal variation in temperature are widely known to affect the seasonality of marine invertebrate recruitment (e.g. McDougall 1943, Osman 1977, Sutherland \& Karlson 1977, Stachowicz et al. $2002 b)$ in the same way that seasonal patterns of temperature and moisture might affect the seasonal phenologies of annual plants, so we think this approach may be appropriate for a variety of systems. While competitive interactions can influence the magnitude of recruitment to some extent, our previous analyses of
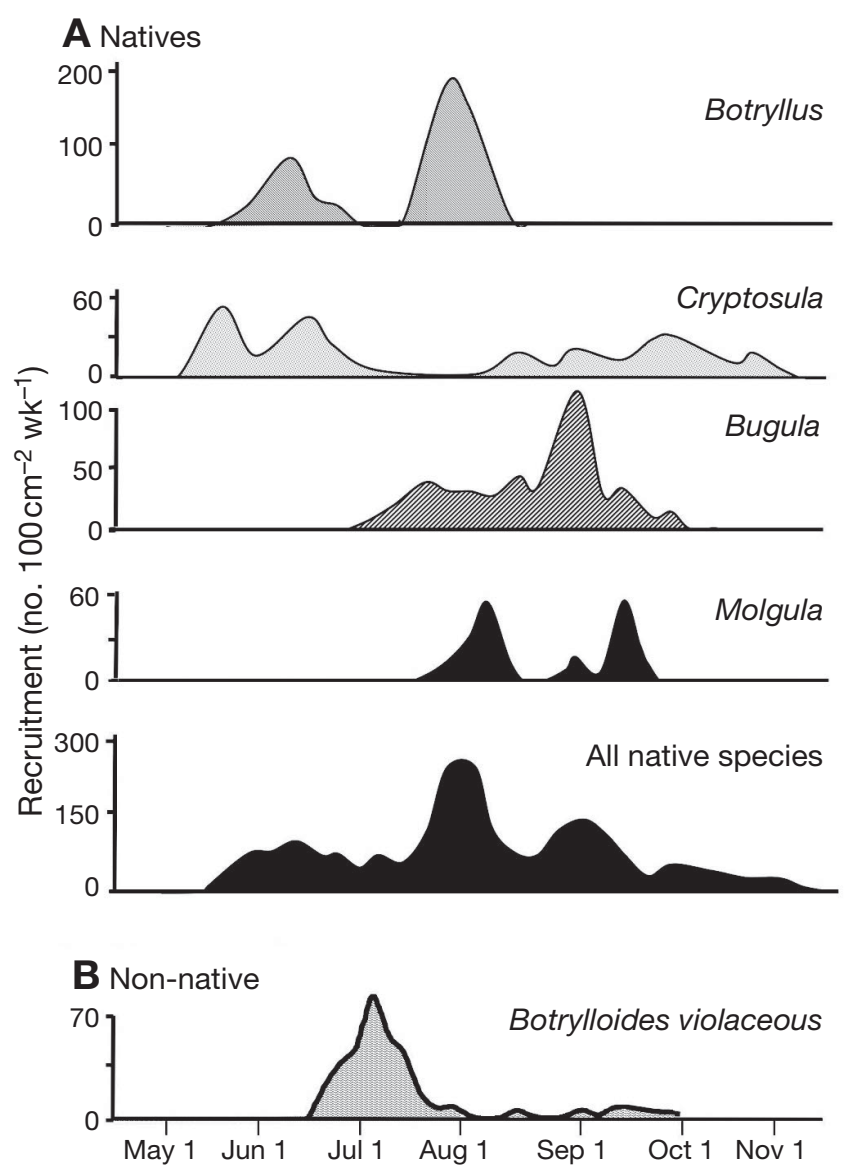

Fig. 2. Settlement of dominant marine invertebrate species at Avery Point, Connecticut, for the 1999 recruitment season. (A) Four of the more abundant native species (Botryllus schlosseri, Cryptosula pallasiana, Bugula turrita, Molgula manhattensis) and the record of all 4 species together, showing the complementary nature of their settlement patterns. (B) Settlement record for the introduced ascidian Botrylloides violaceous. Note that its recruitment pattern coincides with a period of relatively low recruitment by the resident species, particularly the ecologically similar resident species B. schlosseri 
these long-term data find that a large proportion of the variance in the timing of recruitment within species is attributable to within- and between-year variation in temperature (Stachowicz et al. 2002b).

Given these assumptions, we used our weekly recruitment data to assess how total recruitment might change as a function of the number of species recruiting into the community, as well as the extent to which invasion resistance was conferred by temporal complementarity versus individual species with consistently high recruitment. Recruitment can be plotted over time for each species to give a description of the ability of each species to fill new space that becomes available over the course of the season (Fig. 2A). We then assembled all possible combinations of species in each year, and tallied the total number of weeks that recruitment was $>100$ ind. $100 \mathrm{~cm}^{-2}$ panel for each species combination as a measure of the number of weeks per year that space might be saturated by the recruits of resident species. Species that never exceeded 5 recruits
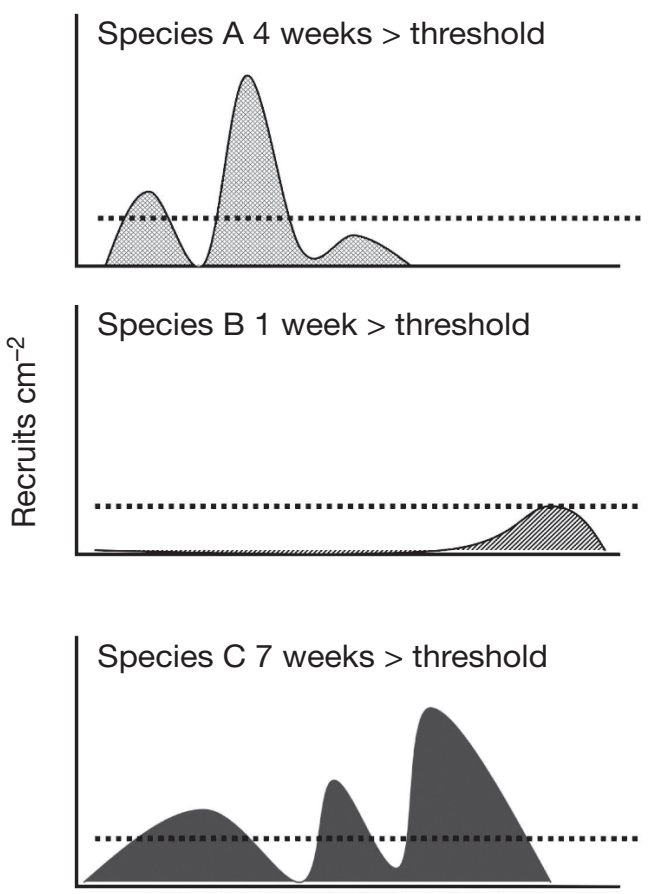

Time $\mathrm{wk}^{-1}$ in a given year were excluded from the simulation. For a given year in which $n$ species $\left(a_{1}, a_{2}, \ldots a_{n}\right)$ were recorded, we produced recruitment records for hypothetical communities that included all possible combinations of $\left(a_{1}, a_{2}, \ldots a_{n}\right)$. For example, if 3 species $(\mathrm{A}, \mathrm{B}$, and $\mathrm{C})$ were recorded in a year, we would assemble recruitment records for the 7 combinations shown in Fig. 3. For each combination we would record both the total number of weeks above the threshold recruitment and the number of weeks that the best species in that combination would be above the threshold if it occurred by itself. While it is obvious that the total number of recruits will increase as one adds species to the assemblage, whether this will increase the number of weeks above a threshold recruitment level depends on the degree to which species have complementary temporal patterns of recruitment. The multi-year record we have allows us to examine the extent to which the strength of such complementarity varies among years.
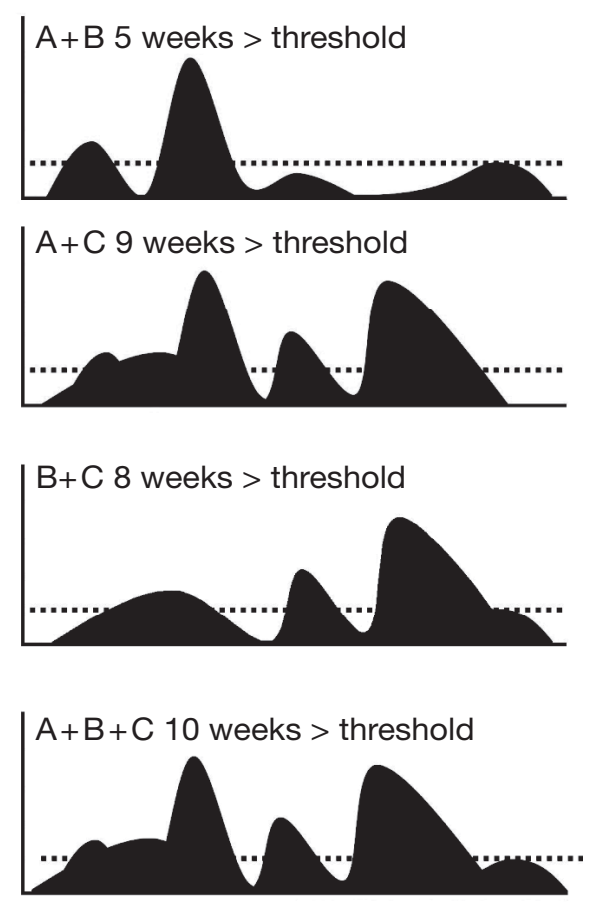

Time

\begin{tabular}{|c|c|c|}
\hline $\begin{array}{l}\text { Species } \\
\text { richness }\end{array}$ & $\begin{array}{c}\text { Average } \\
\text { combination (wk) }\end{array}$ & $\begin{array}{c}\text { Average of best single species } \\
\text { in each combination (wk) }\end{array}$ \\
\hline 1 & 4 & 4 \\
\hline 2 & $(5+9+8) / 3=7.33$ & $(4+7+7) / 3=6$ \\
\hline 3 & 10 & 7 \\
\hline
\end{tabular}

Fig. 3. Diagrammatic depiction of the methods used for assembling hypothetical communities of varying species richness and assessing the number of weeks that the recruitment for that assemblage exceeded a recruitment threshold (dotted line) indicative of saturation (thresholds of $0.1,0.5,1$, or 2 ind $\mathrm{cm}^{-2}$ were used in the analysis). The table at the bottom of the figure shows how the values of number of weeks at saturation were obtained for both the diverse assemblages and the best-recruiting single species in each assemblage 
We initially chose a threshold of 100 ind. $100 \mathrm{~cm}^{-2}$, based on the assumption that even the smallest species in our survey would occupy at least $1 \mathrm{~cm}^{2}$ as an adult or persistent juvenile, so recruitment levels of 100 ind. $100 \mathrm{~cm}^{-2}$ should be sufficient to completely occupy available space within a short period of time and reduce invasion. We also ran the simulation for recruitment thresholds of 10, 50, and 200 recruits $100 \mathrm{~cm}^{-2} \mathrm{wk}^{-1}$, to see if the results were sensitive to the threshold we chose. In reality, substrate saturation would be a more continuous variable, but the results obtained were robust to the choice of threshold value, so our relatively arbitrary choice of threshold is probably of little significance (see below and Fig. 4B).

No one species produced enough recruitment for the entire season to saturate the community (e.g. data for 1998 recruitment year, Fig. 4A). In 1998, the best single species occupied only $9 \mathrm{wk}$ at $>100$ recruits $100 \mathrm{~cm}^{-2}$, compared to 21 wk for the maximum diversity assemblage. Thus, $57 \%$ of the weeks that exceeded the threshold of 100 recruits $100 \mathrm{~cm}^{-2}$ would not have done so without some complementarity among species. While the actual percent of the maximum attained by the bestrecruiting single species is sensitive to the threshold set for recruitment saturation, the patterns hold regardless of which threshold we used (Fig. 4B). Only when the threshold is set as low as 10 recruits $100 \mathrm{~cm}^{-2} \mathrm{wk}^{-1}$, did we see the best-recruiting species begin to approximate the maximum diversity assemblage (Fig. 4B). In our experience, recruitment this low is relatively uncommon and would not be sufficient to inhibit establishment of additional species. However, even at this probably unreasonably low recruitment threshold, having the full complement of species increased the period of saturation by $6 \mathrm{wk}$ from 21 to $27 \mathrm{wk}$ $(22 \%)$. These simple simulations suggest that, for a range of potential saturating recruitment thresholds, complementarity in seasonal recruitment patterns is likely to lead to more consistent space occupation and thus increased resistance to invasion in diverse communities (Stachowicz et al. 2002a).

Because species vary among years in the timing and magnitude of their recruitment, the degree to which seasonal complementarity results in enhanced recruitment saturation may vary among years. We assembled all possible combinations for 3 yr with differing recruitment patterns (Fig. 4C). These data suggest that, while
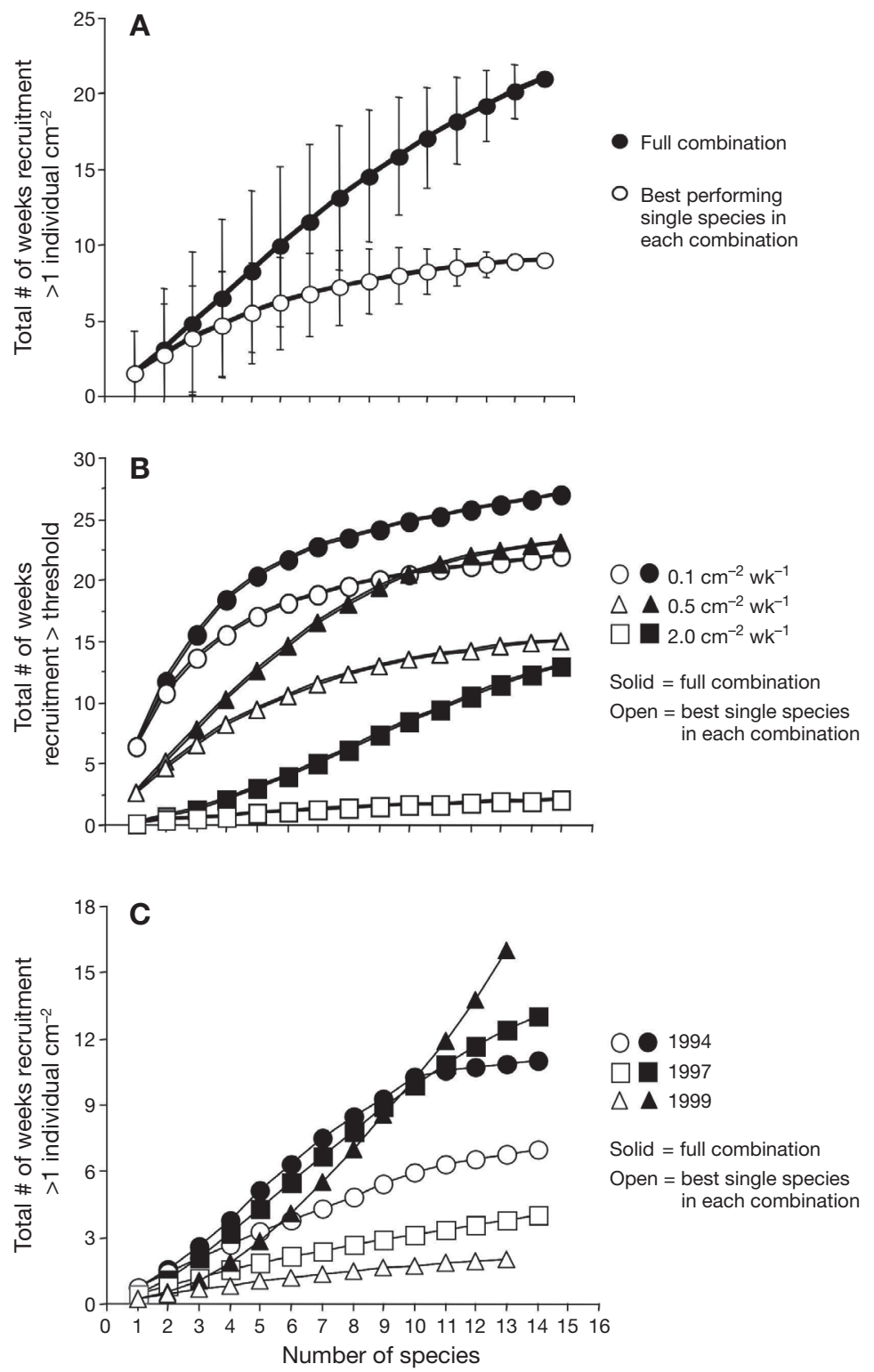

Fig. 4. Number of weeks in which recruitment exceeds the saturation threshold for hypothetical communities assembled from the long-term recruitment records as a function of the number of species in that community. (A) Data for the year 1998, showing separate curves for mean $( \pm 1 \mathrm{SD})$ values of number of weeks above a threshold of 1 recruit $\mathrm{cm}^{-2}$ for the mean of all combinations at each level of richness and for the best-recruiting species in each combination. (B) Effect of changing the threshold value $\left(0.1,0.5,2.0 \mathrm{~cm}^{-2} \mathrm{wk}^{-1}\right)$ of recruitment saturation on the relationship between diversity and number of weeks above the threshold recruitment for 1998. (C) Assembly of communities for 3 additional years that span a range of temperature conditions

the general phenomenon is consistent, the degree to which a single species can saturate recruitment surfaces does vary among years. In 1994, for example, the best-recruiting species reached the threshold on its own for $7 \mathrm{wk}$, while the all-species combination reached the threshold for only 11 ; thus the diversity 
added only 4 wk of 'resistance' (36\% of total resistance due to complementarity). In other years the effect was more dramatic: in 1999 the diverse assemblage saturated $16 \mathrm{wk}$, while the best monoculture reached the threshold for only 2 (86\% of 'saturation' due to complementarity). With such interannual variation, the effects of diversity on invasion success might vary substantially among years depending on the degree to which species were complementary in their seasonal niches. Thusfar, interannual success of invasive species in these communities has been assessed primarily in response to abiotic factors, but incorporating interannual variation in the strength of biotic interactions might prove informative.

For example, of the 3 yr depicted above, the strength of complementarity (percent of weeks above the threshold not accounted for by the best-recruiting species) increases with decreasing native recruitment. In 1994, when winter temperatures were coldest and native recruitment highest, complementarity was relatively weak (36\%); 1997 was an intermediate year in temperature, native recruitment, and complementarity $(69 \%) ; 1999$ was one of the warmest years on record, with low native recruitment and the highest complementarity (88\%) (see Stachowicz et al. 2002b for further exploration of temperature effects). These limited data suggest that complementarity might become more important as the recruitment of individual resident species declines. Intuitively, when total resident recruitment is lower, no one species has high recruitment, so complementarity among species in excluding invaders becomes more important; this explains why the number of weeks above threshold for the bestrecruiting species varies across years. However, it does not explain why the total number of weeks above the threshold is greatest in years with lowest recruitment. Unfortunately, we cannot use these data to independently assess the effect of changing biotic resistance on invasion across years, because increasing temperature has a direct positive effect on the introduced species (Stachowicz et al. 2002b).

Whether interannual variability in complementarity translates into differences in invasion success will also depend on the invader's seasonal recruitment patterns. While diversity should decrease the overall probability of invasion, theory and some empirical work suggest that the degree to which the invader's traits fill a void in the native community plays a role (e.g. Elton 1958, Fargione et al. 2003, Tilman 2004, Stachowicz \& Tilman 2005). Predicting the success of particular invaders within the framework set forth thusfar requires, not only knowing how many invader propagules arrive, but when during the season they arrive. There is evidence that some invaders recruit during 'lulls' in native recruitment. For example, Botrylloides viola- ceous recruits during the early summer, approximately 4 wk after the peak recruitment of Botryllus schlosseri, when few other natives are recruiting (Fig. 2B). In the year depicted in Fig. 2 (1999), in its peak week B. violaceous had 72 recruits $100 \mathrm{~cm}^{-2}$, which was more than all natives combined in that week. The timing of $B$. violaceous recruitment is sensitive to interannual variations in winter and spring temperature, whereas that of many natives, like B. schlosseri is not (Stachowicz et al. $2002 \mathrm{~b}$ ). Thus, the extent to which the recruitment of invaders 'fills holes' in the native community and the success of those invaders may vary among years, possibly leading to interannual variation in the strength of biotic resistance. This point remains speculative, however, as we have no consistent, independent measure of invasion success across years with which to test this hypothesis. Nevertheless, it seems reasonable to suggest that this 'ecological fitting' (sensu Janzen 1985) may be most critical during the establishment phase of the invasion and may determine the species or genotypes of invaders that can succeed in a new community. Once invaders build up a resident population, a large degree of overlap in the timing of recruitment might be more easily tolerated.

\section{EFFECT OF SPATIAL HETEROGENEITY ON NATIVE-INVADER DIVERSITY CORRELATIONS}

While it is clear that fluctuating resources may determine invasion success in a wide variety of communities (Davis et al. 2000), temporal shifts in the abundance of species is only 1 potential cause of such fluctuations. As previously discussed, positive native-invader diversity relationships may reflect that areas with conditions that favor high native diversity will be able to support more invasive species. Within an area of consistent environmental conditions, diversity and invasion should be negatively related (see Fig. 1 in Shea \& Chesson 2002). Thus, from positive correlations alone, it is not appropriate to conclude that decreasing native diversity via extinction would decrease invasion success. Instead, given a mechanistic reason to expect diversity per se to decrease invasion (Fig. 1), species extinction should consistently increase the susceptibility of any area to invasion, leading to an increase in invader species richness with every species extirpated from an area.

However, there are possible mechanisms by which increased diversity might lead mechanistically to increased invasion. Some of these have been explored in a similar epifaunal invertebrate community in Tasmania, where a positive correlation between native and invader diversity was found in temporally repeated surveys of sessile invertebrates that had naturally colonized a rock jetty (Dunstan \& Johnson 2004). 
In their study, species-rich patches consisted primarily of small colonies with rapid turnover, which may provide increased opportunity for the colonization of these patches by new species. Interestingly, although the hypothesized outcome is contrary to that shown in Fig. 1, the underlying mechanism (consistency of space occupancy) is the same. Unfortunately, it is not clear from this survey approach alone what the underlying causes of the differences in colony size among patches might be. Extrinsic conditions may differ significantly among patches, and forces that maintain small colony size (e.g. recent disturbance, grazing intensity, high propagule supply) enhance diversity of both resident and colonizing species.

A second means by which species richness might enhance colonization rates is via interspecific facilitation. Increasing community richness might increase the probability of including species that facilitate the colonization and establishment of a broad range of new species (see discussion in Crooks 2002, Bruno et al. 2003). Dunstan \& Johnson (2004) offer several examples of positive associations among species as a mechanism for a positive native-exotic richness correlation, although similar responses of species to extrinsic factors could also explain such patterns. Our own work has also shown positive pairwise interactions among natives and exotics (Stachowicz et al. 2002a). Still, such pairwise positive interactions will not, by themselves, result in a significant positive correlation between native and non-native diversity.

To further explore the extent to which positive correlations between native and invader diversity are mechanistic versus the result of environmental covariates, we included measurements of relevant resources and other covariates into the statistical model for invader diversity. As our resource reflecting competition and other temporal processes, we sampled for percentage of open space within plots (Stachowicz et al. 2002a). We also consider the effects of the presence and cover of the head-forming bryozoan Watersipora subtorquata on the native-invader diversity relationship, because the 3-dimensional growth form of this animal provides secondary space for colonization by both natives and non-natives (Floerl et al. 2004) and may increase habitat heterogeneity that might facilitate coexistence (Chesson 2000).

We surveyed the docks of the Spud Point Marina in Bodega Bay, California, during the summer of 2004. Five $0.125 \mathrm{~m}^{2}$ quadrats were haphazardly placed on every southern facing slip. Two of these quadrats were located on finger piers, while 3 were on the main pier itself. This was repeated for all 5 docks of the marina (89 slips, $\mathrm{n}=440$ quadrats). Quadrats were visually surveyed for every species present. We used a multiple regression model to examine the effects of native rich- ness and the percentage of open space on invader species richness. We also included an interaction term in each model, in order to examine whether the nativeinvader richness relationship changes under different levels of available space.

While there was no overall correlation between native and invader diversity $\left(F_{1,436}=2.28, \mathrm{p}=0.124\right)$, and a slightly negative correlation between available open space and native diversity $\left(F_{1,436}=25.4, \mathrm{p}<\right.$ $0.0001)$, there was a significant native diversity $\times$ free space interaction $\left(F_{1,436}=3.78, \mathrm{p}=0.05, \mathrm{r}^{2}=0.170\right)$. Specifically, at high levels of open space, there was a strong positive relationship between native and invader richness, whereas, at low levels of open space, the slope of the relationship did not differ from 0 (Fig. 5A). Similarly, there was a strong negative correlation between open space and invader diversity at low levels of native diversity, while the relationship became nearly flat at high levels of native diversity. The reduced invader diversity at high open space is likely due to non-selective disturbance agents that affect native and invader diversity in a similar negative manner, resulting in native and invader richness covarying positively as a reflection of extrinsic factors (e.g. Levine 2000, Shea \& Chesson 2002).

When resources are limiting (low space availability), experimental results predict a negative slope to the relationship between native and invader diversity, but the data instead show a flat relationship (Fig. 5A). As diversity increases, temporal complementarity among species may increase the consistency of space occupation and decrease the likelihood of invader establishment, as argued above. It could be that at low space availability this complementarity simply balances out the effects of extrinsic factors, resulting in a flat native-exotic richness relationship. However, increasing diversity may also increase the likelihood of adding individual species with facilitative effects to the community (Mulder et al. 2001, Cardinale et al. 2002), which could alter the slope of the native-exotic relationship (Bruno et al. 2003). For example species such as Watersipora subtorquata might support epibiotic growth, effectively increasing the surface area available for colonization (i.e. increasing levels of available resource) and potentially negating the effects of enhanced biotic resistance.

When we added the percent cover of Watersipora subtorquata to the regression model, there was a significant 3-way interactive effect of $W$. subtorquata cover, native diversity, and amount of open space on the number of exotics present $\left(F_{1,433}=5.59, \mathrm{p}=0.018\right)$. To visualize this 3 -way interaction, we ran 2 separate analyses, partitioning the data into plots with $>10 \%$ or $<10 \%$ W. subtorquata cover. When W. subtorquata cover is $>10 \%$, there is a consistent positive relation- 
A All data: facilitators common
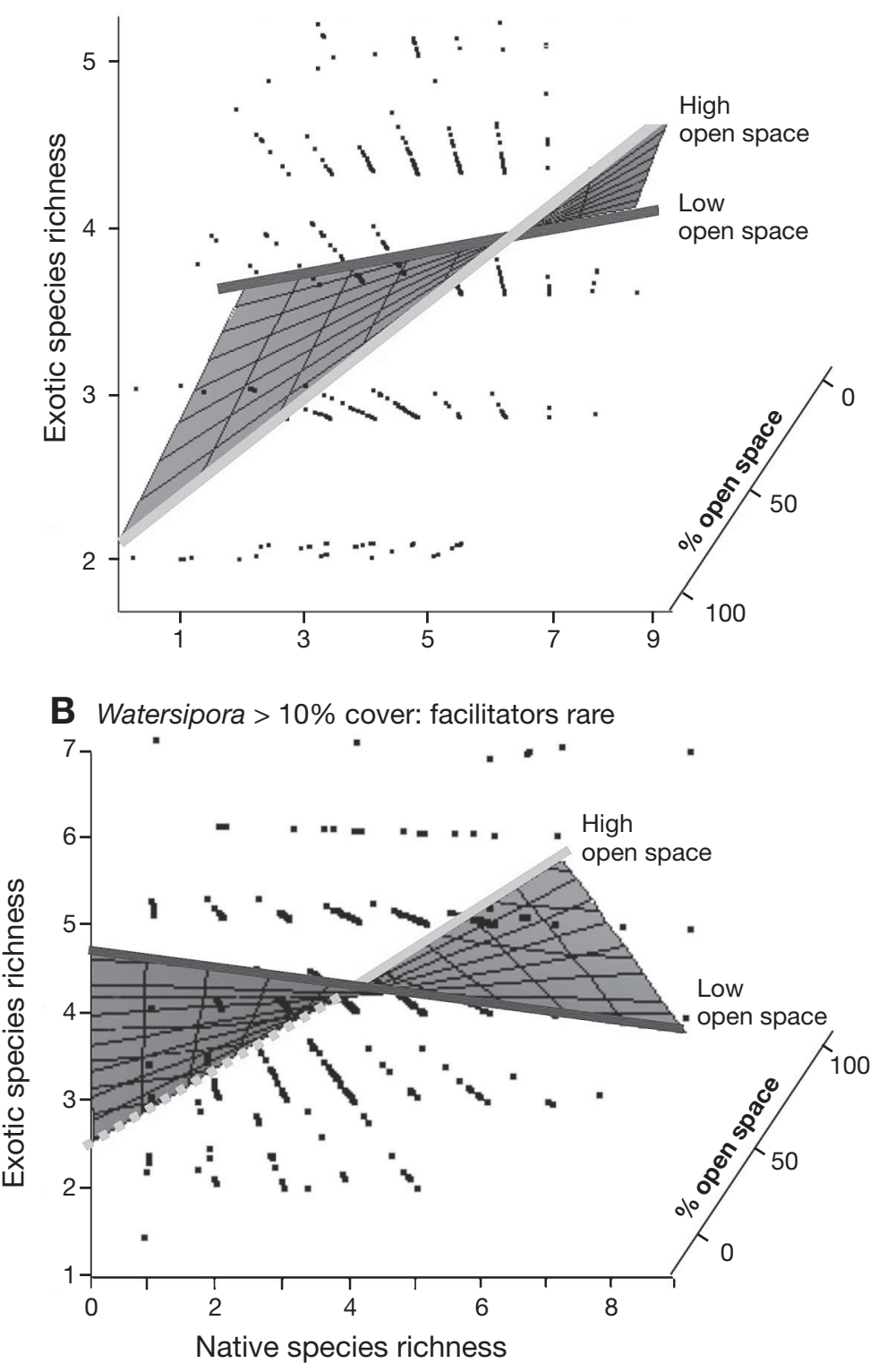

Fig. 5. Regression planes showing how the slope of the relationship between native and invader richness changes as a function of the amount of resources available (percent open space) and the presence of structurally complex species that provide additional attachment sites for sessile species. (A) Data for all plots, showing that as resources become limiting (as open space approaches 0 ) the slope of the relationship between native and invader richness decreases from strongly positive to nearly flat. (B) Data for plots in which the cover of the headforming bryozoan Watersipora subtorquata is $\leq 10 \%$, showing that the native-invader relationship becomes negative when $W$. subtorquata is absent and space is limiting. These figures combined suggest the following: (1) when resources (open space) are not limiting, the mechanism underlying biotic resistance cannot operate, and natives and invader diversities are positively correlated; (2) as free space becomes limiting, the signal of biotic resistance becomes stronger, shifting the relationship to negative at low levels of available space; and (3) the effect of biotic resistance can be offset by the presence of species (facilitators) that provide secondary substrate on their shells or tests, alleviating the resource limitation ship between native diversity and exotic diversity, regardless of the level of open space (open space $F_{1,360}=1.17, \mathrm{p}=0.28$; native richness $F_{1,360}$ $=6.72, \mathrm{p}=0.001$; interaction $F_{1,360}=0.14, \mathrm{p}=$ $\left.0.70, \mathrm{r}^{2}=0.070\right)$. In contrast, when $W$. subtorquata is rare ( $<10 \%$ cover $)$, there is a significant interactive effect of the availability of open space and native diversity on invader diversity $\left(F_{1,74}=5.99, \mathrm{p}=0.018, \mathrm{r}^{2}=0.430\right)$ : the native-invader relationship is positive at high levels of open space, but becomes negative at low levels of open space (Fig. 5B). We regularly observed many different species growing on dead and live parts of the W. subtorquata colony, and the 3-dimensional structure of colonies suggests that $W$. subtorquata may provide more space resources than it uses up. However, it may not just be that $W$. subtorquata provides more space, but that it increases heterogeneity, including the subdivision of space into discrete patches. Indeed, a recent analysis suggests that spatial heterogeneity may be the key to understanding how native-exotic correlations change across spatial scales (Davies et al. 2005).

These data suggest that the presence of a structure-forming species can alleviate space limitation and increase the number of both native and exotic species that can coexist in a given area, masking or eliminating the importance of biotic resistance. Interestingly, the field survey by Stachowicz et al. (2002a), one of the few to show a negative invader-native richness relationship in field survey data, was conducted in a system that lacked abundant foundation species such as these and had low availability of free space. Factorial field manipulations of space availability and facilitator presence are needed to more directly test their effect on biotic resistance, but these conclusions are in accord with those from other studies showing that exotic habitat modifiers often increase the diversity of both natives and exotics (e.g. Crooks 2002). Although our discussions here consider space as the relevant limiting resource in fouling communities, in principle this could work for any sort of resource limitation in other types of communities. For example, in nitrogen-limited terrestrial plant communities, it would be interesting to consider native-exotic relationships across gradients in nitrogen availability and the presence of N-fixing species such as legumes.

The results of these and other surveys suggest that the diversity of both native and introduced species often respond similarly to spatial variation in environmental conditions, leading to pos- 
itive correlations between native and invader diversity (Shea \& Chesson 2002, Davies et al. 2005). This is particularly apparent when resources are not limiting (high amount of open space). However, as available resources become scarce, invader diversity is ultimately determined by a mix of competitive and facilitative interactions between natives and invaders that control resource availability (summarized in Table 1). Looking at the shape of the relationships between native diversity, available resources (both primary and secondary space), and invader diversity can elucidate which of these processes are acting within a system, how they determine the invasibility of the system, and the relative importance of biotic resistance.

\section{CONCLUSION AND APPLICATION TO BROADER DIVERSITY-FUNCTION STUDIES}

The few studies on the relationship between diversity and invasion in marine systems are most noteworthy for their emphasis on assessing the mechanism(s) underlying the patterns of native-invader diversity relationships. The balance of the evidence suggests that diversity can and does enhance resource use, such that fewer resources remain unused over time in more diverse communities. Because resource use will relate to so many other ecosystem functions, these results provide a firm mechanistic basis for the diversityfunctioning relationship. For example, if more diverse communities have higher resource utilization, then they are also likely to have greater biomass or productivity and lower losses of energy or nutrient resources than less diverse communities. The suggestion that diversity enhances the consistency of resource use and space occupancy (e.g. Figs. 1B \& 2A) lends further evidence to the idea that diversity is related to community stability. For instance, in terrestrial studies and theoretical work, as diversity increases, the stability of individual species' populations tends to decrease slightly
(May 1974), whereas the stability of aggregate community properties, such as biomass or percent coverage, tends to increase (Tilman 1996, Tilman \& Lehman 2001). This is exactly what we have found in our study of diversity and invasion (Stachowicz et al. 2002a).

However, when resources do not limit invasion-or more broadly, when resource availability or use does not affect an ecosystem process-then the mechanisms we have identified can be overwhelmed by other factors. For example, as suggested above, the presence of a facilitator can generate additional resources that enhance both native and non-native species, leading to higher diversity of both (e.g. Crooks 2002). However, most work to date has been on sessile taxa, and resource limitation may be less common in other groups (e.g. mobile species). It would be interesting to test the robustness of diversity-invasibility relationships within such groups. Of course mechanisms other than resource depletion might link diversity and invasibility, and other papers in this Theme Section explicitly illustrate how diversity and other ecosystem functions can be linked via a variety of non-competitive mechanisms.

Our results and those of others (e.g. Levine 2000) suggest that the synthesis of observational, experimental, and simulation approaches, such as presented here, might also be profitable when examining the effect of diversity on other ecosystem functions. Indeed, observational approaches tested by Emmerson \& Huxam (2002) show promise for gaining insight into diversity-functioning relationships at larger scales and in high-diversity communities. Given the importance of the ocean to global ecosystem functioning, it seems clear that small-scale experiments will not be sufficient.

Finally, at least in the short term, many invasions have resulted in a net gain in the number of species present at the local/regional level (Sax \& Gaines 2003). This is not surprising and is similar to what is seen in geological-scale invasions: most regions gain in the

Table 1. Summary of how the effects of native richness on invader richness might change as a function of the availability of resources (open space) and the presence or absence of facilitators. Predictions based on data trends in Fig. 5

\begin{tabular}{|lll|}
\hline & Low native richness & High native richness \\
\hline $\begin{array}{l}\text { Low fraction } \\
\text { of resources } \\
\text { available }\end{array}$ & $\begin{array}{l}\text { Biotic resistance overwhelmed by invaders } \\
\text { Invader-invader competition may reduce } \\
\text { invader diversity } \\
\text { INVADER DIVERSITY HIGH TO MODERATE }\end{array}$ & $\begin{array}{l}\text { Biotic resistance reduces invasion success } \\
\text { Greater likelihood of facilitator presence that } \\
\text { increases diversity of natives and invaders } \\
\text { INVADER DIVERSITY LOW TO MODERATE }\end{array}$ \\
$\begin{array}{l}\text { High fraction } \\
\text { of resources } \\
\text { available }\end{array}$ & $\begin{array}{l}\text { Exploitative competition and biotic } \\
\text { resistance unimportant }\end{array}$ & $\begin{array}{l}\text { Exploitative competition and biotic resistance } \\
\text { unimportant }\end{array}$ \\
& by extrinsic factors (e.g. recruitment, disturbance, flow) & $\begin{array}{l}\text { Native and invader diversity determined by } \\
\text { extrinsic factors (e.g. recruitment, disturbance, flow) } \\
\text { INVADER DIVERSITY HIGH }\end{array}$ \\
\hline
\end{tabular}


total number of species, though some resident species eventually go extinct (e.g. Marshall et al. 1982, Vermeij 1991). The diversity-ecosystem functioning debate has mostly been framed in the context of what will happen to ecosystem functioning as species richness declines due to extinctions. But in cases where invasions cause a net increase in diversity at the scale at which ecosystem processes are measured, it is worth considering what effects this might have on ecosystem functioning. There are virtually no data to address this question, although it is clear that invasive species can affect ecosystem structure and function. For example, ecosystems lacking dominant filter-feeding organisms (either because natives have been driven ecologically extinct or because there were none to begin with) are dramatically altered when such species are introduced (e.g. Alpine \& Cloern 1992). Assessing the effects of invasion-caused increases in diversity on a range of ecosystem processes would allow for a more robust test of the diversity-functioning relationship. Additionally, such studies would contribute to a fuller understanding of the degree to which ecosystem functioning saturates at high levels of diversity and provide a more balanced view of the consequences of species introductions.

Acknowledgements. Thanks to Martin Solan for organizing this Theme Section and to 4 anonymous reviewers for comments that improved the manuscript. R. Whitlatch and R. Osman initiated the long-term recruitment record and generously permitted the use of these data for this paper. Maintenance of long-term data collection has been funded by the National Science Foundation (grants from Biological Oceanography and Long-Term Research in Environmental Biology) and the Jessie B. Cox Charitable Trust. Additional support for the work described in this paper was provided by NSF Awards OCE 00-82049 and 03-51778 to J.J.S. C. Coates assisted in the collection of field data in California.

\section{LITERATURE CITED}

Alpine AE, Cloern JE (1992) Trophic interactions and direct physical control of phytoplankton biomass in an estuary. Limnol Oceanogr 37:946-955

Bruno JF, Stachowicz JJ, Bertness MD (2003) Inclusion of facilitation into ecological theory. Trends Ecol Evol 18: 119-125

Buss LW (1979) Bryozoan overgrowth interactions: the interdependence of competition for space and food. Nature 281:475-477

Byers JE, Noonburg EG (2003) Scale dependent effects of biotic resistance to biological invasion. Ecology 84: 1428-1433

Cardinale BJ, Palmer MA, Collins S (2002) Species diversity enhances ecosystem functioning through interspecific facilitation. Nature 415:426-429

Carlton JT, Geller JB (1993) Ecological roulette: the global transport of nonindigenous marine organisms. Science 261:78-82

Case TJ (1990) Invasion resistance arises in strongly inter- acting species-rich model competitive systems. Proc Natl Acad Sci USA 87:9610-9614

Chesson P (2000) Mechanisms of maintenance of species diversity. Annu Rev Ecol Syst 31:343-366

Crooks JA (2002) Characterizing ecosystem level consequences of biological invasions: the role of ecosystem engineers. Oikos 97:153-166

Davies KF, Chesson P, Harrison S, Inouye BD, Melbourne BA, Rice KJ (2005) Spatial heterogeneity explains the scale dependence of the native-exotic diversity relationship. Ecology 86:1602-1610

Davis MA, Grime JP, Thompson K (2000) Fluctuating resources in plant communities: a general theory of invasibility. J Ecol 88:528-534

Duffy JE, Stachowicz JJ (2006) Why biodiversity is important to oceanography: potential roles of genetic, species, and trophic diversity in pelagic ecosystem processes. Mar Ecol Prog Ser 311:179-189 (in this Theme Section)

Dunstan PK, Johnson CR (2004) Invasion rates increase with species richness in a marine epibenthic community by two mechanisms. Oecologia 138:285-292

Elton CS (1958) The ecology of invasions by animals and plants. Methuen, London

Emmerson M, Huxham M (2002) How can marine ecology contribute to the biodiversity-ecosystem functioning debate? In: Loreau M, Naeem S, Inchausti P (eds) Biodiversity and ecosystem functioning: synthesis and perspectives. Oxford University Press, Oxford, p 139-146

Fargione J, Brown CS, Tilman D (2003) Community assembly and invasion: an experimental test of neutral versus niche processes. Proc Natl Acad Sci USA 100:8916-8920

Floerl O, Pool TK, Inglis GJ (2004) Positive interactions between nonindiginous species facilitate transport by human vectors. Ecol Appl 14:1724-1736

Grosholz ED (2002) Ecological consequences of coastal invasions. Trends Ecol Evol 17:22-27

Janzen D (1985) On ecological fitting. Oikos 45:308-310

Kennedy TA, Naeem S, Howe KM, Knops JMH, Tilman D, Reich P (2002) Biodiversity as a barrier to ecological invasion. Nature 417:636-638

Klimley AP, Richert JE, Jorgensen SJ (2005) The home of blue water fish. Am Sci 93:42-49

Knops JMH, Griffin JR, Royalty AC (1995) Introduced and native plants of the Hastings reservation, central coastal California, a comparison. Biol Conserv 71:115-123

Knops JMH, Tilman D, Haddad NM, Naeem S and 7 others (1999) Effects of plant species richness on invasion dynamics, disease outbreaks, insect abundances and diversity. Ecol Lett 2:286-293

Lavorel S, Prieur-Richard AH, Grigulis K (1999) Invasibility and diversity of plant communities: from patterns to processes. Divers Distrib 5:41-49

Levine JM (2000) Species diversity and biological invasions: relating local process to community pattern. Science 288: 852-854

Levine JM, D'Antonio CM (1999) Elton revisited: a review of evidence linking diversity and invasibility. Oikos 87:15-26

Lonsdale WM (1999) Global patterns of plant invasions and the concept of invasibility. Ecology 80:1522-1536

Marshall LG, Webb SD, Sepkoski JJ, Raup DM (1982) Mammalian evolution and the Great American interchange. Science 215:1351-1357

May RM (1974) Stability and complexity in model systems, 2nd edn. Princeton University Press, Princeton, NJ

McDougall KD (1943) Sessile marine invertebrates of Beaufort, North Carolina: a study of settlement, growth and seasonal fluctuations among pile-dwelling organisms. 
Ecol Monogr 13:321-374

McGrady-Steed J, Haris PM, Morin PJ (1997) Biodiversity regulates ecosystem predictability. Nature 390:162-165

Mulder C, Uliassi D, Doak D (2001) Physical stress and diversity-productivity relationships: the role of positive interactions. Proc Natl Acad Sci USA 98:6704-6708

Naeem S, Knops JMH, Tilman D, Howe KM, Kennedy T, Gale S (2000) Plant diversity increases resistance to invasion in the absence of covarying extrinsic factors. Oikos 91: 97-108

Osman RW (1977) The establishment and development of a marine epifaunal community. Ecol Monogr 47:37-63

Planty-Tabacchi AM, Tabacchi E, Naiman RJ, Deferrari C, Decamps H (1996) Invasibility of species-rich communities in riparian zones. Conserv Biol 10:598-607

Rejmanek M (1996) Species richness and resistance to invasions. In: Orians GH, Dirzo R, Cushman JH (eds) Biodiversity and ecosystem processes in tropical forests. Springer-Verlag, Berlin, p 153-172

Rejmanek M (2003) The rich get richer response. Frontiers Ecol Environ 1:122-123

Ruiz GM, Fofonoff PW, Carlton JT, Wonham MJ, Hines AH (2000) Invasion of coastal marine communities in North America: apparent patterns, processes, and biases. Annu Rev Ecol Syst 31:481-531

Rynearson T, Armbrust V (2004) Genetic differentiation among populations of the planktonic marine diatom Ditylum brightwellii (Bacillariophyceae). J Phycol 40:34-43

Sax DF (2002) Native and naturalized plant diversity are positively correlated in scrub communities of California and Chile. Divers Distrib 8:193-210

Sax DF, Gaines SD (2003) Species diversity: from global decreases to local increases. Trends Ecol Evol 18:561-566

Shea K, Chesson P (2002) Community ecology as a framework for biological invasions. Trends Ecol Evol 17:170-176

Stachowicz JJ, Tilman D (2005) Species invasions and the relationship between community saturation, diversity and ecosystem functioning. In: Sax DF, Stachowicz JJ, Gaines SD (eds) Species invasions: insights into ecology,

Editorial responsibility: Martin Solan (Guest Editor), Newburgh, UK evolution, and biogeography. Sinauer, Sunderland, MA, p 41-64

Stachowicz JJ, Whitlatch RB, Osman RW (1999) Species diversity and invasion resistance in a marine ecosystem. Science 286:1577-1579

Stachowicz JJ, Fried H, Whitlatch RB, Osman RW (2002a) Biodiversity, invasion resistance and marine ecosystem function: reconciling pattern and process. Ecology 83: $2575-2590$

Stachowicz JJ, Terwin JR, Whitlatch RB, Osman RW (2002b) Linking climate change and biological invasions: ocean warming facilitates non-indigenous species invasions. Proc Natl Acad Sci USA 99:15497-15500

Stohlgren TJ, Binkley D, Chong GW, Kalkhan MA and 6 others (1999) Exotic plant species invade hot spots of native plant diversity. Ecol Monogr 69:25-46

Sutherland JP, Karlson RH (1977) Development and stability of the fouling community at Beaufort, N.C. Ecol Monogr $47: 425-446$

Symstad A (2000) A test of the effects of functional group richness and composition on grassland invasibility. Ecology 81:99-109

Tilman D (1996) Biodiversity: population vs. ecosystem stability. Ecology 77:350-363

Tilman D (2004) A stochastic theory of resource competition, community assembly and invasions. Proc Natl Acad Sci USA 101:10854-10861

Tilman D, Lehman C (2001) Biodiversity, composition and ecosystem processes: theory and concepts. In: Kinzing AP, Pacala SW, Tilman D (eds) The functional consequences of biodiversity. Princeton University Press, Princeton, NJ, p 9-41

Van Name WG (1945) The North and South American ascidians. Bull Am Mus Nat Hist 84:1-475

Vermeij GJ (1991) Anatomy of an invasion: the trans-Arctic interchange. Paleobiology 17:281-307

Wiser SK, Allen RB, Clinton PW, Platt KH (1998) Community structure and forest invasion by an exotic herb over 23 years. Ecology 79:2071-2081

Submitted: April 22, 2005; Accepted: November 10, 2005

Proofs received from author(s): March 3, 2006 